Est Ag 53 (2018) 5-36

\title{
Género y registro del evangelio de Marcos desde la perspectiva sociolingüística
}

\author{
Alfredo Delgado Gómez (Adsis)
}

RESUMEN La identificación del género literario del evangelio de Marcos sigue siendo un problema abierto. La sociolingüística aporta herramientas como son los conceptos de registro, género, estilo, etc., que pueden poner luz en este callejón sin salida. Este artículo presenta la relación sinérgica que se establece al analizar el registro y el género del evangelio de Marcos. Esta relación permite comprender mejor la acción social que quiere desarrollar el evangelista con su texto en su comunidad. Existen diferentes géneros posibles como candidatos para el evangelio de Marcos, sin embargo se propone que el análisis y la comparación de éstos, ha de tener en cuenta la relación que se establece entre el género, el registro y el estilo de los mismos, para poder desde ahí realizar una propuesta sobre el género del evangelio de Marcos. El registro del evangelio se presenta como narrativo, histórico, religioso y judío, y su género cercano a la historiografía y las biografías de la antigüedad. La conexión de estos dos factores permite entender mejor su género y desechar otras propuestas.

PALABRAS CLAVE: Género, registro, sociolingüística, narratividad, biografías antiguas.

ABSTRACT: The identification of the literary genre of Mark's gospel remains an open problem. The socio-linguistics provides tools such as the concepts of register, gender, style, etc., that can put light in this impasse. This article presents the synergetic relationship that is stablished when it is analyzed the register and the genre of Mark's gospel. This relationship allows a better understanding of the social action that the evangelist wants to develop with his text in his community. There are different possible genres as candidates for the gospel of Mark, nevertheless it is proposed that the analysis and comparison of these genre must take into account the relationship established between the genre, the register and the style, in order to make a proposal about the gospel genre of Mark. The register of the gospel is presented as narrative, historical, religious and Jewish, and its genre is close to the historiography and biographies 
of antiquity. The connection of these two factors allows a better understanding of their gender and discarding other proposals.

KEYWORDS: Genre, register, sociolinguistics, narrative, ancient biography.

\section{INTRODUCCIÓN}

El evangelio de Marcos es un texto cercano a cumplir los dos mil años de antigüedad y viene de un país extraño. Su país nos resulta extraño porque no conocemos exactamente dónde surgió y también porque en general, "el pasado es un país extraño". Se nos hace difícil en muchos aspectos, pero especialmente cuesta situarse en el ámbito de los géneros literarios, que resultan complejos y no siempre claros. El evangelio de Marcos es un buen ejemplo de un texto antiguo que se sigue resistiendo a una clasificación unívoca dentro del ámbito de los géneros literarios que nos son conocidos de la antigüedad clásica y del antiguo oriente próximo.

Este artículo pretende acercarse a la problemática del género literario del evangelio de Marcos desde la sociolingüística, conscientes de las múltiples perspectivas con las que se puede y se debe abordar un fenómeno tan complejo como es el del género literario ${ }^{2}$. Para ello se procederá presentando aquellos conceptos y definiciones que propone la sociolingüística y que afectan a la comprensión del género literario. Posteriormente se aplicarán estas herramientas al evangelio de Marcos intentando extraer algunas conclusiones que puedan iluminar desde otro ángulo su género literario.

\section{LA SOCIOLINGÜístiCA Y SU APLICACIÓN AL NT}

La sociolingüística como disciplina dentro de la Lingüística ya lleva un cierto recorrido. Autores precursores fueron Malinowski, Firth y Labov, con sus estudios sobre las diferencias sociales en el habla ${ }^{3}$. Se fue constatando

${ }^{1}$ Lowenthal, D., El pasado es un país extraño, Madrid 1998.

${ }^{2}$ ZYMner, R. D., Handbuch Gattungstheorie, Stuttgart 2010.

${ }^{3}$ Malinowski, B., "The problem of Meaning in Primitive Languages", en MaLinowsKi, B.-Ogden, C.K.-Richards, I.A.-Crookshank, F.G.-Postgate, J.P. (eds.), The meaning of meaning: A study of the influence of language upon thought and of the science of symbolism New York 1923, 296-336. FiRTH, J.R.-PALMER, F.R., Selected papers of J. R. Firth, 1952-59, Bloomington 1968. LABOV, W., "The boundaries of words and their meanings", en BAILEY, C.-J. N.SHUY, R.W. (eds.), New ways of analyzing variation in English, Washington, DC 1973, 340-373. 
que conocer las reglas de la sintaxis no explicaba las múltiples concreciones que aparecen en el lenguaje, ni el porqué de esas elecciones. La sociolingüística estudia cómo se utiliza el lenguaje en la sociedad, cuáles son las funciones sociales del mismo y cómo influyen diferentes factores sociales en el uso de la lengua. La pregunta de Bell resulta sintetizadora: ¿por qué este emisor dice esto en esta ocasión y de esta manera ${ }^{4}$ ? La sociolingüística tiene un amplio abanico de aplicaciones y de ámbitos de estudio: desde el estudio de las variedades sociales del habla (donde se abordan fenómenos como diglosia, multilingüismo, codeswichting, etc.) hasta el estudio antropológico del habla y su relación con el pensamiento y la cosmovisión.

Dos autores pioneros en la sociolingüística moderna fueron Ferguson y Fishman con sus estudios sobre diglosia y multilingüismo ${ }^{5}$. Halliday y McIntosh plantearon las relaciones entre uso de la lengua y situación extralingüística, perspectiva reformulada posteriormente en estudios importantes como el de Gregory y Carroll ${ }^{6}$. Existen buenas introducciones entre las que destacan Hudson, Wardhaugh, Romaine ${ }^{7}$. Obras colectivas importantes son Bayley y Ammon ${ }^{8}$.

La sociolingüística se ha aplicado al estudio del NT en diversos aspectos: diglosia, multilingüismo, etc. Pionero en su aplicación fue Moisés Silva con un artículo sobre bilingüismo ${ }^{9}$. Actualmente se encuentran algunos estudiosos que aplican esta disciplina al NT como Porter, Lee, Ong y

${ }^{4}$ BELL, A., "Back in style: reworking audience design", en ECKERT, P.-RICKFORD, J.R. (ed.), Style and sociolinguistic variation, Cambridge 2001, 139-169, p. 139.

${ }^{5}$ Ferguson, C.A., "Diglossia", en Word 15 (1959) 325-340. Ferguson, C.A., "Dialect, register, and genre: Working assumptions about conventionalization", en BIBER, D.-FINEGAN, E. (eds.), Sociolinguistic perspectives on register, Oxford 1994, 15-30. Fishman, J.A., "Who speaks what language to whom and when?", en La linguistique 1:2 (1965) 67-88.

${ }^{6}$ Halliday, M.A.K.-McIntosh, A.-Strevens, P., The linguistic sciences and language teaching, London 1964. Gregory, M.-CARroll, S., Lenguaje y situación variedades del lenguaje y sus contextos sociales, México 1986.

${ }^{7}$ Hudson, R.A., Sociolinguistics, Cambridge ${ }^{2}$ 1996. Wardhaugh, R., An introduction to sociolinguistics, West Sussex, $\mathrm{UK}^{6} 2010$. RomaIne, S., El lenguaje en la sociedad: Una introducción a la sociolingüística, Barcelona 1996.

${ }^{8}$ BAyley, R.-CAmeron, R.-Lucas, C., The Oxford handbook of sociolinguistics, Oxford 2013. Ammon, U., Sociolinguistics: an international handbook of the science of language and society = Soziolinguistik: ein internationales Handbuch zur Wissenschaft von Sprache und Gesellschaft (=Handbücher zur Sprach- und Kommunikationswissenschafts 3.1;3.2;3.3), Berlín ${ }^{2}$ 2004.

${ }^{9}$ SILVA, M., "Bilingualism and the character of Palestinian Greek", en Biblica 61 (1980) 198-219. 
Pitts, entre otros ${ }^{10}$. También se aplica en los estudios clásicos con autores como Willi, o Consani que aplican la sociolingüística al griego antiguo ${ }^{11}$.

\section{TERMinología Y CONCEPTOS DE LA SOCIOLINGÜÍ́TIICA}

A continuación, se presentan cuatro definiciones provenientes de la sociolingüística: variedad, registro, género y estilo. Son cuatro conceptos claves para poder comprender mejor el relato de Marcos, paso primero para entender su obra en su contexto.

\section{Variedad}

El concepto sociolingüístico variedad denota los diferentes modos de hablar que se utilizan en distintas situaciones. Este concepto quiere incluir las múltiples posibilidades que aparecen en el uso del lenguaje. Es decir, utilizando la misma lengua, con el mismo vocabulario y sintaxis se producen diferentes modalidades en el hablar, dadas las infinitas posibilidades de combinación que ofrece el lenguaje. Existen variaciones permanentes y transitorias $^{12}$. Las permanentes aglutinan al idiolecto, al dialecto, al geolecto, etc. Entre las transitorias se encuentran el registro, el estilo y el modo. Halliday distingue entre variedades debidas al usuario (dialecto) y al uso (registro $\left.^{13}\right)$.

${ }^{10}$ PorTER, S.E., "Sociolinguistics and New Testament Study", en Linguistic Analysis of the Greek New Testament: Studies in Tools, Methods, and Practice, Grand Rapids, MI 2015, 113131. LEE, S.-I., Jesus and Gospel traditions in bilingual context: a study in the interdirectionality of language (=BZNW 186), Berlin 2012. ONG, H.T., The multilingual Jesus and the sociolinguistic world of the New Testament (=Linguistic biblical studies 12), Leiden 2016. PITTS, A.W., "Style and Pseudonymity in Pauline Scholarship: A Register Based Configuration”, en Porter, S.E. (ed.), Paul and pseudepigraphy, Leiden 2013,113-151.

${ }^{11}$ Consani, C., "Ancient Greek Sociolinguistics and Dialectology", en GiannaKis, G. (ed.), Encyclopedia of Ancient Greek Language and Linguistics 1, Leiden 2014.

${ }^{12}$ CATFord, J. C., A linguistic theory of translation: an essay in applied linguistics, London 1965, 84-85. También se pueden señalar las diferencias sincrónicas (sociolectos, geolectos, etc.) y diacrónicas (etapas y evolución de una lengua).

${ }^{13}$ HALLIDAY, M.A.K.-HASAN, R., Language, context, and text: aspects of language in a social-semiotic perspective, Oxford ${ }^{2} 1989,41$. 


\section{Registro}

La noción de registro se entiende como el uso lingüístico determinado por el contexto inmediato de producción de un discurso ${ }^{14}$. Para Wardhaugh registro es un conjunto de elementos del lenguaje asociados con grupos sociales u ocupaciones concretas (pilotos, banqueros, etc.) o con una institución. Las personas que participan en situaciones recurrentes tienden a emplear el mismo vocabulario, expresiones y entonación ${ }^{15}$. A esta clase de variación se le llama registro ${ }^{16}$. El principal interés de estudio de la variedad de registros es cómo el lenguaje segmenta la experiencia lingüística y sirve para clasificar los eventos lingüísticos ${ }^{17}$. Según Hudson tu dialecto muestra quién eres, mientras que tu registro muestra qué estás haciendo ${ }^{18}$.

A la hora de definir un registro Biber ${ }^{19}$ propone analizar determinados marcadores del registro ${ }^{20}$ como su interactividad, las circunstancias de producción, la implicación personal, grado de abstracción, la narratividad ${ }^{21}$ y la argumentación o persuasión ${ }^{22}$.

${ }^{14}$ Wardhaugh, An introduction to sociolinguistics, 52. Para la definición de registro es fundamental la relación entre texto y contexto. BIBER, D.-FinEGAN, E., Sociolinguistic perspectives on register, Oxford 1994, 6-7.

${ }^{15}$ Ferguson, "Dialect, register, and genre", 20.

${ }^{16} \mathrm{El}$ término registro fue introducido por REID, T.B.W., "Linguistics, structuralism and philology", en Archivum Linguisticum 8 (1956) 28-37.

${ }^{17}$ URE, J., "Introduction. Approaches to the study of register range", en International Journal of the Sociology of Language 35 (1982) 5-23, p. 9.

${ }^{18}$ Hudson, Sociolinguistics, 46.

${ }^{19}$ Biber, D., "An analytical framework for register studies", en Biber, D.-FinEGAN, E. (ed.), Sociolinguistic perspectives on register, Oxford 1994, 31-56. BIBER, D., Dimensions of register variation: a cross-linguistic comparison, Cambridge 1995, 236-270.

${ }^{20}$ Para analizar Willi prefiere hablar de patrones recurrentes más que de solo marcadores del registro, porque éstos no son nunca exclusivos de un único registro. WiLLI, A., "Register Variation", en BAKKer, E.J. (ed.) A companion to the ancient Greek language, Oxford 2010, 297-310, p. 300.

${ }^{21}$ Características: Verbos en pasado, pronombres de terceras personas, adverbios temporales y oraciones subordinadas.

${ }^{22}$ Marcada por los verbos modales, las subordinadas condicionales, las conjunciones concesivas, etc. 


\section{Dominio}

El término dominio se utiliza para denotar el contexto social de interacción ${ }^{23}$. Un dominio institucional debe describirse en términos sociológicos y económicos y comprende un conjunto de ocasiones de uso del lenguaje que surgen porque la sociedad se organiza de determinada manera. Dominios típicos de una comunidad discursiva son la familia, la religión, la educación, el trabajo y la amistad. Dominios como el transporte y la educación evolucionan rápidamente por los cambios sociológicos y tecnológicos, sin embargo la religión es un dominio donde la continuidad es más fuerte. Cada uno tiene unos factores específicos: destinatario, contexto $\mathrm{y}$ topic ${ }^{24}$.

Los dominios no son lo mismo que los registros. Un registro es una manifestación de un idioma, mientras que un dominio es una característica de una comunidad. En este sentido un dominio puede hacer uso de más de un idioma. El conjunto de dominios es específico de una cultura mientras que los registros son específicos del lenguaje y requieren ser descritos en términos de lingüística descriptiva. Cada dominio hace uso de un grupo de registros, y un mismo registro se puede encontrar en muchos dominios ${ }^{25}$.

\section{Estilo}

Con la categoría estilo se han definido diferentes fenómenos y dista de llegarse a un acuerdo ${ }^{26}$ ya que con él se denotan aspectos relacionados con diversas variedades del lenguaje ${ }^{27}$. Es un hecho que una misma persona puede adoptar diferentes estilos y adecuarse a determinados audito-

${ }^{23}$ Término propuesto por FISHMAN, J.A., "Language maintenance and language shift as fields of inquiry", en Linguistics 9 (1964) 32-70.

${ }^{24}$ Otros autores proponen el lugar, la relación entre participantes y el topic.

${ }^{25}$ URE, "Introduction. Approaches to the study of register range", 8.

${ }^{26}$ Hernández CAmpoy, J.M., Sociolinguistic styles, West Sussex, UK 2016, xviii.

27 "Generally, style is used to refer to formal/informal linguistic features and register is used to refer to situationally defined language varieties". WILLI, "Register Variation", 298. Sobre el estilo y la clase social Bernstein, B., "Social Class and Sociolinguistic", en Ammon, U.DittMar, N.-MATtheIER, K.J. (eds.), Sociolinguistics 2 (=HSK 3.2; Berlin²2004) 1287-1303. Sobre el estilo es clave Coupland, N., Style: language variation and identity, Cambridge 2007. Sobre lenguaje e identidad EDWARDS, J., Language and identity: an introduction, Cambridge 2009. MENDOZA-Denton, N., "Language and Identity", en Chambers, J.K.-Trudgill, P.-Schilling-Estes, N. (eds.), The handbook of language variation and change, Malden, MA 2002, 475-499. 
rios en función de la edad, la formalidad, la importancia, la elegancia, etc. Siempre que se habla o escribe se ve uno afectado por convenciones sociales, lingüísticas y por las expectativas de los destinatarios ${ }^{28}$. La elección de un determinado estilo tiene más bien un significado social ${ }^{29}$, es decir, a través del estilo el hablante se intenta vincular a un determinado grupo social. En este artículo y siguiendo a diferentes autores el concepto estilo hace referencia a la formalidad del discurso ${ }^{30}$, el cual se ve condicionado por el contexto y por diferentes factores: la relación entre los participantes, el ámbito donde se desarrolla (casa, trabajo), el tipo de acto de habla, la emoción, etc. ${ }^{31}$. Se habla en este sentido de cinco niveles de formalidad ${ }^{32}$ desde esta perspectiva del estilo.

\section{Género}

Desde la perspectiva sociolingüística el género es un tipo de mensaje que aparece regularmente en una comunidad (en términos de contenido semántico, participantes, ocasiones de uso) y que tiende en el tiempo a adoptar una estructura interna que le permite ser diferenciada de otros tipos de mensajes dentro del repertorio de la comunidad ${ }^{33}$. Diferentes géneros corresponden a distintas maneras de usar el lenguaje para cumplir con diversas tareas culturalmente definidas, y los textos de distintos géne-

${ }^{28}$ Haynes, J., Style, London 1995, 7 y 32. Por ello, el estilo se puede estudiar desde la situación concreta, desde la comunidad discursiva a la que se dirige, o centrado en el hablante. Desde la perspectiva del emisor, el código que se escoge para una ocasión determinada indica cómo quiere ser visto por los otros. Por tanto, el estilo que se escoge es tan importante como el código que se utiliza.

${ }^{29}$ HyMEs, D.H., Foundations in sociolinguistics; an ethnographic approach, Philadelphia 1974, 434. Tabouret-Keller, A., "Language and identity", en Coulmas, F. (ed.), The Handbook of Sociolinguistics, Oxford 1997, 315-326, p. 317.

${ }^{30}$ Trudgill, P., The social differentiation of English in Norwich, Cambridge 1974, 46. Heylighen, F.-Dewaele, J.-M., "Formality of language: definition, measurement and behavioral determinants", en Center "Leo Apostel”, Vrije Universiteit Brüssel (1999) 1-38.

${ }^{31}$ Romaine, El lenguaje en la sociedad, 96-100.

${ }^{32}$ Martin Joos identificó cinco grados de formalidad: "intimate, casual, consultative, formal, frozen". Joos, M., The five clocks, New York 1962. Fragmentación, integración, desapego y participación son las propuestas de CHAFE, W.L., "Integration and Involvement in Speaking, Writing, and Oral Literature", en TANNEN, D. (ed.), Spoken and written language: exploring orality and literacy, Norwood, N.J 1982, 35-53.

${ }^{33}$ Ferguson, "Dialect, register, and genre", 21. Género desde la lingüística funcional en GeEst, D. DE-Gorp, H. VAN, "Literary genres from a systemic \& functionalist perspective", en European Journal of English Studies 3 (1999) 33-50. 
ros son aquellos que realizan diferentes propósitos en la cultura ${ }^{34}$. No se entiende el género tanto por sus características formales, sino por la relación funcional entre su estructura y la situación. Hanks entiende el género y el texto como marcos orientativos, abiertos al cambio. No están cerrados, sino que contienen elementos prototípicos desde los cuales los actores pueden seguir interpretando el acto discursivo ${ }^{35}$.

Un texto es considerado como una unidad compleja, temática y conceptualmente coherente a través de la cual se realiza un acto verbal con un significado comunicativo específico. Por tanto, lo que hace a un texto desarrollar un género no es su forma lingüística sino la acción retórica que opera como respuesta a las dinámicas de un contexto social ${ }^{36}$. Desde este punto de vista, los géneros son estrategias sociales para hacer algo ${ }^{37}$.

La intención y la función de un texto se constituyen a través de factores internos, pero también a través de factores externos como el destinatario, la situación, la relación entre los interlocutores, el origen social ${ }^{38}$, etc. Sin embargo, es cuestionable si tal marco analítico es suficiente para desarrollar una clasificación totalmente coherente de los tipos de texto y sus características y funciones ${ }^{39}$. Es evidente, que para comprender un texto se

\footnotetext{
${ }^{34}$ EgGins, S.-MARTin, J.R., "El contexto como género: una perspectiva lingüística funcional”, en Revista signos 36:54 (2003) 185-205, p. 202.

${ }^{35}$ HANKs, W., "Discourse genres as a theory of practice", en American Ethnologist 14:4 (1987) 668-692, p. 681.

${ }^{36}$ Sune Auken afirma que no se pueden obviar las características formales y estructurales a la hora de definir el género. Auken, S., "Utterance and Function in Genre Studies: A Literary Perspective", en ANDERsen, J. (ed.), Genre Theory in Information Studies, Bingley, UK 2015,155-178. Esta forma de entender el género es similar a la de la historia de las formas, para la cual la busqueda del Sitz im Leben consideraba los textos desde el punto de vista de su función. THEISSEN, G., Urchristliche Wundergeschichten: ein Beitrag zur formgeschichtlichen Erforschung der synoptischen Evangelien, Gutersloh 1974, 12.

37 "Los géneros son procesos por etapas orientados a un fin". MARTIN, J.R., "Genre and literacy-modeling context in educational linguistics", en Annual review of applied linguistics 13 (1992) 141-172, p. 142.

${ }^{38}$ Los factores externos que encontramos en los primitivos papiros cristianos como son su preferencia por el códice, el tamaño de la página, sus márgenes amplios, los títulos de los evangelios, la tendencia a agrupar los evangelios, el tipo de letra (bookhand), los nomina sacra, son factores evidentes de la voluntad de la comunidad cristiana de dotar de identidad a sus escritos, claramente reconocibles de otros escritos pertenecientes a otras comunidades discursivas. Los papiros literarios griegos se encueran siempre en rollos y nunca en códices, todo lo contrario de los papiros y manuscritos cristianos. Los judíos optan por el rollo y por la piel tratada.

39 "A text is regarded as a complex, thematically and conceptually coherent unit through which a verbal act with a specific communicative meaning is performed. The intention and
} 
necesitan varios polos, ya que el género literario por sí mismo no responde a todas las preguntas ${ }^{40}$. Por tanto es necesario comprender el género analizado desde su intención y características formales, la relación con su registro, así como la situación en la que se desarrolla, la comunidad discursiva a la que se dirige ${ }^{41} \mathrm{y}$ las relaciones intertextuales que quiere provocar el texto, unido a la cosmovisión que maneja el texto.

\section{Relación sinérgica entre género y registro}

Para la sociolingüística es muy importante la relación entre los conceptos de género y registro, ya que a la hora de definir un texto es necesaria la conjunción de ambos. En este sentido, registro es el código lingüístico que se usa en la creación de un texto que pertenece a un género ${ }^{42}$. El registro $^{43}$ tiene que ver con situaciones comunicativas recurrentes mientras que el género tiene que ver con tipos de mensajes recurrentes ${ }^{44}$. Ambas generarán unos marcadores lingüísticos, lexicales y estructurales diferentes a otros tipos de situaciones o tipos de mensaje. Para Swales el género impone restricciones en el ámbito de la estructura del discurso, mientras que el registro lo hace en los niveles gramatical y lingüístico ${ }^{45}$.

Un ejemplo puede ayudar a captar la relación entre registro y género literario desde la perspectiva de Ferguson, donde el registro es una variedad

function of a text is constituted through internal factors, but also through external factors such as addressee, situation, relationship between communicative partners, social background, etc. It is, however, questionable whether such an analytical framework is sufficient to develop a fully coherent classification of text types and their characteristics and functions". FöGEN, T., "Technical Literature", en Hose, M.-Schenker, D.J. (eds.), A companion to Greek literature, Chichester, UK 2015, 266-279, p. 267.

${ }^{40}$ Derrida fue un claro exponente del ocaso de los estudios literarios sobre el género.

41 "Genre is also defined by 'audience, context of performance, circulation of texts, and self-aware critical discussion' along with the 'emotional expectations' of readers". GoLDHILL, S., "Genre", en Whitmarsh, T. (ed.), The Cambridge companion to the Greek and Roman novel, Cambridge 2008, 185-200, p. 186-187.

${ }^{42}$ WILLI, A., The languages of Aristophanes: aspects of linguistic variation in classical Attic Greek, Oxford 2003, 8.

${ }^{43}$ BIBER, Dimensions of register variation, 9.

${ }^{44}$ WILLI, "Register Variation”, 298.

${ }^{45}$ SwAlEs, J., Genre analysis: English in academic and research settings, Cambridge 1990, 41 cita a Couture, B., Functional approaches to writing: research perspectives, London 1986, 82. El género es una categoría semántica porque relaciona los factores socioculturales y las formas lingüísticas. 
debida al uso relacionada con una situación recurrente y el género es un tipo de mensaje. Podemos hablar del registro que utiliza el piloto de un avión. Este comunica determinados mensajes en una situación recurrente y a una comunidad discursiva muy concreta. Ese piloto tiene muchos más registros en su haber, pero como piloto de la aeronave se comunica con los pasajeros utilizando un registro concreto. Sin embargo, en este registro puede enunciar varios tipos de mensajes y puede utilizar diferentes géneros literarios disponibles, que son identificados por unas características concretas y sobre todo por su función, que es la que ayuda a interpretar el mensaje. Es decir, haciendo uso del mismo registro y dirigiéndose a los pasajeros (la comunidad discursiva) puede enunciar diferentes tipos de mensajes. Por ejemplo, puede informar de las condiciones del tiempo en el aeropuerto de llegada, dar órdenes ante un contratiempo en el viaje, pedir un médico ante una emergencia dentro del avión, dar órdenes solo a la tripulación, etc. Sin embargo, un guía turístico puede realizar los mismos actos de habla con la misma intención que el piloto (dar órdenes, informar, etc.), es decir, comparten el género literario, pero no así el registro. Por lo tanto, para entender sus actos comunicativos hay que conocer sus géneros y registros.

\section{Registro y género en la SFL}

La Lingüística Sistémico Funcional (SFL) de Mark Halliday ${ }^{46}$, que es así mismo una teoría sociolingüística ${ }^{47}$, ha propuesto una definición de registro específica, el cual se entiende como el uso lingüístico determinado por el contexto inmediato de producción de un discurso ${ }^{48}$. Halliday no ha presentado sistemáticamente su concepto de registro, pero en sus escritos distingue las variaciones del lenguaje en función del contexto de la cultura y de la situación ${ }^{49}$. El contexto de la cultura (dentro del cual está el género) hace referencia a los condicionantes culturales que hacen posible el lenguaje, es decir, el lenguaje está situado históricamente ${ }^{50}$. El contexto de la

${ }^{46}$ Halliday, M.A.K., El lenguaje como semiótica social: la interpretación social del lenguaje y del significado, México 1982.

${ }^{47}$ Halliday de hecho fue alumno de Firth.

${ }^{48}$ Cervantes, C.V., "Registro”, en Martín Peris, E. (ed.), Diccionario de términos claves de ELE, Madrid 2008.

${ }^{49}$ Halliday-Hasan, Language, context, and text, 41.

${ }^{50}$ Para Halliday el dialecto hace referencia a quien es emisor en un sentido social o regional, mientras que el registro hace referencia a qué uso se realiza del lenguaje. CouPLAND, Style, 12. 
situación trata de la situación lingüística que provoca una particular instancia del lenguaje. Envuelve al hablante y al oyente, lector y escritor. Un registro puede ser definido por tres elementos que son tenor, campo y modo ${ }^{51}$. Campo se refiere al evento social que el texto está intentado realizar; tenor al tipo de relaciones sociales que se mantienen entre los emisores y receptores del texto; y modo al tipo de texto, especialmente en términos del canal (oral $\mathrm{u}$ escrito) y su modo retorico, tales como el narrativo, didáctico o persuasivo ${ }^{52}$. También tiene en cuenta el término estilo ${ }^{53}$.

\section{COMPRENDER UN TEXTO. SOCIOLINGÜÍSTICA Y MC}

Antes de analizar la relación entre registro y género en Mc se ha de señalar que comprender un texto es un proceso complejo, más aún si se trata de un texto antiguo ${ }^{54}$. Después de doscientos cincuenta años de estudios críticos ha quedado patente que son necesarios muchos elementos y métodos para poder comprender adecuadamente un discurso. La historia de la interpretación del texto ayuda a tener perspectiva sobre las múltiples visiones que se han tenido del relato y de los logros de distintos métodos a la hora de analizar el evangelio ${ }^{55}$. La hermenéutica ha reflexionado profun-

51 "En primer lugar, el lenguaje escrito utilizará menos referencias personales, más vocabulario nominalizado y menos verbos de acción, y los significados estarán empaquetados densamente dentro de frases nominales complejas. Nos referimos a esta dimensión del contexto como el modo. Nuestro segundo grupo de diferencias lingüísticas (la ausencia y/o presencia de elecciones actitudinales y evaluativas) está relacionado con el papel que desempeña el autor de cada texto. Esta dimensión del contexto que corresponde a los papeles se denomina el tenor de una situación. Tanto la expresión técnica del léxico como las fuentes de las referencias intertextuales son indicadores significativos de lo que llamamos el campo del discurso". EgGINs-MARTIN, "El contexto como género", 338-339. Un buen diagrama y explicación en Martin, J.R., "Cohesion and Structure", en Schiffrin, D.-TANnen, D.-HAmiLton, H.E. (eds.), The handbook of discourse analysis, Malden, MA², 2015, 61-81.

${ }^{52}$ Lewin, B.A.-Fine, J.-YounG, L., Expository discourse: a genre-based approach to social science research texts, London 2001, 9.

53 "There are no regions of language in which style does not reside". HALLIDAY, M.A.K., "Linguistic function and literary style: An inquiry into the language of William Golding's The Inheritors", en Weber, J.J. (ed.), The Stylistics Reader: From Roman Jakobson to the Present, London 1996, 56-91, p. 63.

${ }^{54}$ FeEst, U., Historical perspectives on Erklaren and Verstehen, Heidelberg 2010.

${ }^{55}$ Marcus señala que si surge una nueva interpretación hay que sospechar. Sobre la Wirkunsgeschichte de Mc cfr. Collins, A.Y., Mark: A commentary (=Hermeneia 55), Grand 
damente sobre diferentes focos de este proceso, y especialmente en los estudios bíblicos queda clara la sinergia que se puede aprovechar del estudio de la intención del autor, la autonomía del texto y las posibles interpretaciones que pueden elaborar sus lectores ${ }^{56}$.

En este sentido es claro que son muchos los elementos necesarios para poder comprender un texto como Marcos: su dialecto y la concreción en su idiolecto, su estilo literario, su mundo narrativo y cosmovisión, la comunidad a la que se dirige, su autor, sus conexiones intertextuales, etc.

Pero después de muchos años de estudio científico hay que reconocer que ante Marcos hay que situarse con una actitud de humildad científica. Con los datos actuales y en el momento presente de la investigación no es posible llegar a una conclusión definitiva ni sobre su autor, ni sobre la identidad de la comunidad destinataria, ni sobre el lugar de procedencia del evangelio (Roma, Siria, Palestina, etc.). La intención del relato es más o menos clara, pero está escrito con múltiples funciones sociales: histórica, recopilatoria, exhortativa, hermenéutica, etc., como posteriormente se desarrollará. La comunidad discursiva a la que va dirigido (audiencia target) nos es desconocida, pero se puede afirmar que es una comunidad cristiana concreta, que conoce y cree en los textos del AT como revelados por Dios y que participa de la cosmovisión que de ellos emana. Desconocemos las fuentes de las que se sirvió, así como las tradiciones orales con las que contó. No existe un consenso sobre su género literario, entre otros factores porque se desconoce el sistema de géneros literarios tanto orales como escritos de su época, de la que han sobrevivido pocos textos en comparación con los que debieron existir.

Entre los elementos que podemos reconocer como aceptados se puede señalar que se trata de un texto escrito seguramente para ser leído en público $^{57}$. Es un texto literario (uno de los descubrimientos de los últimos 70 años y que ha quedado demostrado y acepado) y no documental, escrito en prosa, en un registro narrativo, semítico y religioso, con múltiples conexiones intertextuales con los libros de la LXX. Es evidente que Mc ha sido escrito en un estilo formal muy sencillo dentro del amplio rango que le era posible, aunque

\footnotetext{
Rapids, MI 2007. KoK, M.J., The Gospel on the Margins: The Ideological Function of the Patristic Tradition on the Evangelist Mark, Grand Rapids, MI 2015. SCHILDGEN, B.D., Power and Prejudice: The Reception of the Gospel of Mark, Detroit 1999. Wrege, H.-T., Wirkungsgeschichte des Evangeliums Erfahrungen, Perspektiven und Moglichkeiten, Gottingen 1981.

${ }^{56}$ Eco, U., Los límites de la interpretación, Barcelona 1992.

${ }^{57}$ Minchin, E., Orality, literacy and performance in the ancient world, Leiden 2012. WIRE, A.C., The case for Mark composed in performance, Eugene, OR 2011.
} 
se trata de una narración estructurada (a pesar de la opinión de Papías de que no tiene orden ${ }^{58}$, con una trama compleja y un final sorprendente y abierto.

A continuación, se estudian solo dos nudos de esta red de aspectos necesarios para comprender un texto como el de Marcos desde el punto de vista sociolingüístico: el género y el registro, aprovechando algunos de los conceptos desarrollados. En este sentido se ha señalado cómo la sociolingüística (y la SFL) provee de unos conceptos que permiten situar mejor el problema del género literario de $\mathrm{Mc}$ al poder relacionarlo con otros elementos como son el registro, el dialecto, el estilo, etc. Especialmente significativa es la relación entre género y registro. Otros elementos importantes serían el dialecto, el idiolecto, su estructura, etc., pero en este artículo solo se puede acometer la relación sinérgica entre género y registro.

\section{GÉNERO E INTENCIÓN EN MC}

En este apartado se analiza el género de Marcos desde la perspectiva sociolingüística, la cual acentúa la intención social del texto. En el siguiente apartado se estudiará el registro de Marcos para posteriormente ponerlos en relación sinérgica.

No es fácil definir el género del evangelio de Mc y de hecho existen diferentes propuestas ${ }^{59}$, bien fundamentadas, que le relacionan con el género de la historiografía judía ${ }^{60}$, la historiografía helenística ${ }^{61}$, las biografías antiguas $^{62}$, la novela ${ }^{63}$, la épica ${ }^{64}$, la tragedia ${ }^{65}$ e incluso durante mucha parte

${ }^{58}$ Eusebio de Cesarea, Historia eclesiástica (ed. A. Velasco Delgado), Madrid 1973, $\S$ III, 39,15, p. 184.

${ }^{59}$ Una buena presentación en Collins, Mark: A commentary, 15-52 y en DieHL, J.A., "What is a gospel?: Recent studies in the gospel genre", en CBR 9 (2011) 171-199.

${ }^{60}$ BAltzer, K., Die Biographie der Propheten, Neukirchen-Vluyn 1975.

${ }^{61}$ BeCKer, E.-M., Das Markus-Evangelium im Rahmen antiker Historiographie (=WUNT 194), Tübingen 2006.

${ }^{62}$ Burridge, R.A., What are the Gospels?: A Comparison with Graeco-Roman Biography, Grand Rapids, MI22004 y FRICKENSCHMIDT, D., Evangelium als Biographie: Die vier Evangelien im Rahmen antiker Erzählkunst, Tübingen 1997.

${ }^{63}$ Este género se ha aplicado a Mc por parte de Tolbert, M.A., Sowing the Gospel: Mark's world in literary-historical perspective, Michigan, MI 1996 y en su variante judía por VINES, M.E., The Problem of Markan Genre: The Gospel of Mark and the Jewish Novel, Leiden 2002.

${ }^{64}$ MacDonald, D.R., The Homeric Epics and the Gospel of Mark, New Haven, CT 2000.

${ }^{65} \mathrm{INCH}$, M.A., Exhortations of Jesus according to Matthew and Up from the Depths: Mark as Tragedy, Lanham, MD 1997. 
del siglo XX se ha comprendido el género literario como una novedad ${ }^{66}$. Lo que no existe es una presentación de las diferentes relaciones posibles entre el registro y el género de estas propuestas. A continuación, se analiza el género desde la perspectiva de la intención social que busca acometer el autor, para ello se analizan las intenciones múltiples de Mc y su registro para establecer una conexión entre ambos elementos.

\section{Múltiples intenciones desempeñadas por el relato de Marcos}

No es posible conocer la intención clara de Marcos a la hora de redactar su relato, pero por el estudio de su narración queda claro que debieron ser varias sus intenciones ${ }^{67}$ y varias también las funciones sociales que debió desempeñar su texto en su comunidad. Para Jakobson el lenguaje puede desarrollar múltiples funciones ${ }^{68}$, y algunas de ellas se pueden rastrear en Mc. Por ello se ha de estudiar el texto de Marcos e intentar comprenderlo como una acción social en respuesta a unas circunstancias ${ }^{69}$ tanto

${ }^{66}$ Es la conclusión de los estudiosos de la Formgeschichte. Dibelius, M., La historia de las formas evangélicas, Valencia 1984. Bultmann, R.K., Historia de la tradición sinoptica, Salamanca 2000. SCHMIDT, K.L., Die Stellung der Evangelien in der allgemeinen Literaturgeschichte, Berlin 1923. El pionero fue Herder. Herder, J.G., "Regel der Zusammenstimmung unser Evangelien, aus ihrer Entstehung und Ordnung", Sammtliche Werke zur Religion und Theologie 17, Tübingen 1830, 169-232. También Overbeck, F., "Über die Anfänge der patristischen Literatur", en Historische Zeitschrift 48 (1882) 417-472, p. 429.

${ }^{67}$ Sobre las funciones de Marcos cfr. Collins, Mark: A commentary, 98-102. DyER, C.H., "The Purpose for the Gospel of Mark", en Toussaint, S.D.-DyER, C.H. (eds.), Essays in Honor of J. Dwight Pentecost, Chicago 1986, 49-62. WINN, A., The purpose of Mark's Gospel: an early Christian response to Roman imperial propaganda (=WUNT II 245), Tübingen 2008. Roskam trata específicamente la relación entre género e intención en Roskam, H.N., The purpose of the Gospel of Mark in its historical and social context, Leiden 2004,11-14. CooK, J.G., The structure and persuasive power of Mark: a linguistic approach, Atlanta 1995. LEMCIO, E.E., "The intention of the evangelist, Mark”, en New Testament Studies 32 (1986) 187-206. MüLler, U.B., "Die christologische Absicht des Markusevangeliums und die Verklärungsgeschichte", en ZNW 64 (1973) 159-193. GUNDRY, R.H., "The Purpouse of Mark”, en Mark: a commentary on his apology for the cross, Grand Rapids, MI 1993, 1022-1026. BRITTON, R., The Theological Intentions of Mark's Literary Devices, London 2016. MouLE, C.F.D., "The intention of the evangelists", en HiGGINS, A.J.B. (ed.), New Testament Essays: Studies in Memory of T.W. Manson 1893-1958, Manchester 1959,165-179.

${ }^{68}$ Para Jakobson las funciones del lenguaje son la emotiva, conativa, referencial, metalingüística, fática y poética. JAKOBSON, R., "La lingüística y la poética”, en Ensayos de Lingüística General, Barcelona 1958, 347-395.

${ }^{69}$ Son múltiples las posibles ocasiones que dieron lugar al escrito: el impacto en la comunidad de la guerra judía, la destrucción del templo, el retraso de la parusía, la muerte de 
externas como internas de su comunidad ${ }^{70}$. Se señalan a continuación algunas de las posibles intenciones del evangelio.

La primera es la intención informativa. Por un lado, el propio evangelio de Marcos se presenta en su título como "comienzo/fundamento de una buena noticia sobre Jesús el Mesías” (Mc 1,1). Por tanto, su intención primaria es la transmisión de una buena noticia ${ }^{71}$. Por otro lado, su prólogo (Mc 1,1-14) sitúa al lector en conexión con la historia hebrea, con el libro de Isaías, en un lugar y tiempo determinado.

Segundo, es claro que Marcos presenta una intención histórica. Desea relatar sucesos que han acontecido, aunque desde el punto de vista de la exégesis actual, su presentación de la historia esté profundamente entretejida con una valoración teológica ${ }^{72}$. Marcos tiene la intención de conservar el legado de los apóstoles una vez que los testigos oculares han desaparecido. Se trata de un ejercicio de memoria social $^{73}$.

los últimos testigos oculares, etc. Sobre las categorías de situación y estrategia cfr. BURKE, K., The philosophy of literary form: studies in symbolic action, Berkeley, CA ${ }^{3} 1974,2$.

${ }^{70}$ Para Nils Dahl Marcos fue escrito con la intención de preservar la tradición que había recibido. No fue escrito con una intención misionera sino para que los creyentes entendieran mejor el significado adecuado del evangelio. El Cristo en el que creen es el Hijo del Hombre oculto que murió como Mesías rechazado. Se trata de un relato que quiere despertar a una comunidad que da por garantizado el evangelio. Hay una llamada la fe y a la resistencia y vigilancia ante la aflicción. DAHL, N., "The Purpose of Mark's Gospel”, en Jesus in the Memory of the Early Church, Minneapolis 1976, 52-65. Para Marxen el final del evangelio muestra que el evangelista esperaba que la parusia tuviera lugar en Galilea, lugar que propone como origen del evangelio. El evangelio fue escrito para una comunidad que huyó en la guerra del 66 y que esperaba el retorno de Jesús. MARXsen, W., El evangelista Marcos, Salamanca 1981. Para John R. Donahue no hay consenso sobre la comunidad y el contexto del evangelio desde que Marxen rompiera el anterior consenso centrado en Roma. Donahue, J.R., "Windows and mirrors: the setting of Mark's Gospel", en The Catholic Biblical Quarterly 57 (1995) 1-26, p. 1.

71 "Presentar la salvación", es el objetivo de Marcos para Dibelius, La historia de las formas evangélicas, 284.

72 "Mc ofrece una interpretación teológica en formato narrativo". Esto fue ya propuesto por Wrede que remarcaba más lo teológico que lo histórico. Wrede, W., Das Messiasgeheimnis in den Evangelien: zugleich ein Beitrag zum Verständnis des Markusevangeliums, Göttingen ${ }^{2} 1913$. También fue reforzado por Johannes Weiss que señaló que era más teológica que histórica la intención de Mc. WeIss, J., Das alteste Evangelium: ein Beitrag zum Verständnis des Markus-Evangeliums und der ältesten evangelischen Überlieferung, Göttingen 1903.

${ }^{73}$ Duling, D.C., "Social Memory and Biblical Studies: Theory, Method, and Application”, en Biblical Theology Bulletin: A Journal of Bible and Theology 36 (2006) 2-4. Sobre memoria y oralidad cfr. EvE, E., "Memory, Orality and the Synoptic Problem", en Early Chris- 
Tercero, Mc tiene una intención persuasiva e interpretativa. Presenta una imagen coherente y unificada de Jesús, donde ha conseguido tejer un relato con sus fuentes interpretadas teológicamente ${ }^{74}$. El evangelista quiere presentar la identidad de Jesús como el Mesías, el Hijo de Dios ${ }^{75}$. Es un relato que tiende hacia la cruz y que intenta dar sentido a su fracaso. Esto debió resultar sorprendente tanto en un ámbito hebreo como helenístico ${ }^{76}$. Nadie mejor que Pablo ha explicado la locura que supone el mensaje que conlleva el evangelio: locura para los griegos y escándalo para los judíos (1Cor 1,23). Se puede afirmar que la identidad de Jesús está en el centro de su narración. Aquí se puede hablar de la importancia del elemento biográfico como medio de su presentación de la identidad de Jesús. Su narración tiene una importante referencia a Jesús como personaje principal, pero Jesús siempre es entendido vinculado a la historia de Israel, de la que es continuación ${ }^{77}$. Jesús es el personaje principal de una etapa de esa historia, donde interactúa con sus discípulos en una trama de acción y de revelación en conflicto con las autoridades político religiosas de su tiempo. En el fondo, Mc está dotando a su comunidad de un relato que le permita entender el mensaje de Jesús, su muerte y resurrección y que lo vincule a las Escrituras judías, interpretando su sentido. Desde una perspectiva sociorreligiosa les ofrece el $\mu \tilde{0} \theta$ os, el relato, de su religión ${ }^{78}$.

tianity 6 (2015) 311-333. BAUCKHAM, R., Jesus and the eyewitnesses: the Gospels as eyewitness testimony, Grand Rapids, MI 2006.

${ }^{74}$ Telford, W.R., "Mark's Portrait of Jesus”, en Burkett, D. (ed.), The Blackwell Companion to Jesus, Oxford 2010, 11-29. Sobre la imagen Richardson, A., Mental imagery, London 1969. Richardson, J.T.E., Mental imagery and human memory, London 1980. MitCHELL, W.J.T., The Language of images, Chicago 1980. Mitchell, W.J.T., Iconology: image, text, ideology, Chicago 1986.

75 "Das MkEv hat sein Ziel im Bekenntnis: "Wahrhaftig dieser Mensch war Sohn Gottes" (15,39)". THEISSEN, Urchristliche Wundergeschichten, 218. Sobre las intenciones de Mc afirma Collins: "One was to reassert the messiahship of Jesus and to redefine it over against the messianic pretenders during the Jewish war that began in $66 \mathrm{CE}$. Another was to interpret actual or expected persecution (or both) as discipleship in imitation of Christ". CoLLINS, Mark: A commentary, 102.

${ }^{76}$ Käsemann señalaba que la intención de Mc era contrarrestar los excesos carismáticos de las comunidades. KäSEMAnN, E., Ensayos exegéticos, Salamanca 1978, 167.

${ }^{77}$ Para Ehrman, la vida de Jesús se presenta como continuación de la historia del AT. EHRMAn, B.D., Forged: writing in the name of God: why the Bible's authors are not who we think they are, New York 2011, 224.

${ }^{78}$ Theissen, G., Erleben und Verhalten der ersten Christen: Eine Psychologie des Urchristentums, Gutersloh 2007, 354-370. 
Cuarto, su narración cohesiona la comunidad. Su relato reúne a su comunidad en torno a Jesús, al presentar los orígenes de la comunidad y de sus instituciones ${ }^{79}$ (apóstoles, eucaristía, el papel de las Escrituras, etc.). Propone un modelo de discipulado y de relación con Jesús (47x aparece la palabra discípulos y sólo hay una escena donde los discípulos no aparecen separados de Jesús). También cohesiona a su comunidad en torno a su autor. Su anonimato debió ejercer al menos dos funciones sociales. Para Baum es un nexo con la historiografía judía y para Berger este anonimato junto con su final abierto son una estrategia para situarse como intérprete privilegiado del evangelio ${ }^{80}$.

Quinto, Mc intenta interpretar la destrucción de Jerusalén y el templo (Mc 13,9-13) y confortar a la comunidad ante las persecuciones que acontecieron en contra de cristianos y judíos, tanto en Roma por Nerón, como las acaecidas como consecuencia de la primera guerra judía. Para Dahl quiere despertar a la comunidad y hacerla permanecer en medio de la tribulación ${ }^{81}$.

\section{Las intenciones de sus compañeros}

Una vez analizadas las intenciones de Marcos, que serán clave para analizar su género, se pueden pespuntar las intenciones de sus posibles pretendientes como compañeros de género.

La intención de la historiografía helenística fue también variada, al ser tan amplia en el tiempo y en géneros ${ }^{82}$. La primera es narrar sucesos que

${ }^{79}$ MARKSChIES, C., Estructuras del cristianismo antiguo un viaje entre mundos, Madrid 2001.

${ }^{80}$ BAUM, A.D., "The Anonymity of the New Testament History Books: A Stylistic Device in the Context of Greco-Roman and Ancient Near Eastern Literature", en Novum Testamentum 50 (2008) 120-142, p. 133 y BERGER, K., Formen und Gattungen im Neuen Testament, Tübingen 2005, 47-53. También IERSEL, B.M.F. VAN, Mark: a reader-response commentary (=JSNTSupS 164), Sheffield 1998, 22.

81 "The emphasis on those points in the narrative which evoke fear and astonishment is a cry to awaken, addressed to a church in danger of taking the Gospel for granted. This call to faith, to endurance in affliction, and to watchfulness is combined with a warning against self-assurance and ambitious strivings". DAHL, "The Purpose of Mark's Gospel”, 52.

${ }^{82}$ Existen muchos géneros en los 700 años que van de Homero a Dión Casio. Se pueden señalar cuatro grandes etapas. Primera, Herodoto y Tucídides son los que establecieron el género historiográfico. Segunda, en el siglo IV vino un cambio en la historiografía motivado por Jenofonte y el influjo de la filosofía. El tercer cambio viene de los cronistas de Alejan- 
han sucedido y cuyo conocimiento aclara e ilumina el presente ${ }^{83}$. La segunda es reforzar la fama del autor, su prestigio social e influencia en su sociedad, dada su omnipresencia en su obra, donde presenta una visión ejemplar y ética de los acontecimientos como refuerzo de su posición política y social ${ }^{84}$. Tercera, la historiografía presenta una intención política, al analizar sus autores las causas de determinadas guerras y sucesos recientes. Cuarta, los relatos historiográficos tienen la intención de formar a una nueva generación de políticos ${ }^{85}$. Quinta, también hay una intención identitaria. La historiografía refuerza la identidad de la nación.

La intención de algunas de las biografías antiguas ${ }^{86}$ era doble: aumentar la fama del autor y destacar la virtud a partir de un personaje ${ }^{87}$. En primer lugar, muchas de las biografías antiguas querían aumentar la fama del autor $^{88}$, por eso es omnipresente en el relato y explicitado en sus prólogos,

dro y queda ejemplificado este estilo en Timeo. El cuarto cambio es durante la época romana ejemplificado en Polibio. SCANLON, T.F., Greek Historiography, Chichester, UK 2015, 276. Jacoby's sub-genres are mythography/genealogy, ethnography, chronography, contemporary history, horography/local history. KRAUS, C.S., "Is historia a Genre?", en PAPANGHELIS T. D. (ed.), Generic Interfaces in Latin Literature: Encounters, Interactions and Transformations, Berlin 2013, 417-432, p. 423.

${ }^{83}$ Para Cicerón el hecho fundamental es narrar la verdad. CiCERÓN, M.T., Institución Oratoria 2,36 y 2,62 .

${ }^{84}$ En varias épocas escribir historia ha sido la prerrogativa de senadores y hombres de estado como Fabio, Catón y Piso. La historia política y las res gestae eran un tema apropiado para un hombre en la vida pública, serio, patriótico y con una función ética y ejemplar. WISEMAN, T.P., "Practice and theory in Roman historiography", en History 66:218 (1981) 375-393, p. 379.

85 "All of historiography's paradigms had a paideutic end and in some sense a political end: to form a governing class, offering it analytical instruments and behavioral models (as in Thucydides); to put forward great personalities, positive or negative, as exempla, so as to fix the parameters of moral evaluation (as with Theopompus, Tacitus, and the biographical tradition); or to construct memory and collective identity (as in local historiography and ktiseis [foundation narratives])". NiCOLAI, R., "The Place of History in the Ancient World", en MARINCOLA, J. (ed.), A companion to Greek and Roman historiography 1, Oxford 2007, 13-26, p. 14. Ya lo señalaba Aristóteles para quien la historia era parte de la política. En este sentido se puede subrayar cómo la influencia de los sofistas fue grande en los impulsores del género.

${ }^{86} \mathrm{La}$ investigación actual señala que no es claro que las biografías antiguas fueran reconocidas como un género literario propio. LiTTLEwOOD, A.R., "Biography and autobiography”, en WiLson, N.G. (ed.), Encyclopedia of Ancient Greece, London 2006, 124-126, p.124 y HäGG, T., The Art of Biography in Antiquity, Cambridge 2012, 2.

${ }^{87}$ DiEHL, "What is a 'gospel'? recent studies in the gospel genre", 193.

${ }^{88}$ BAUM, "The Anonymity of the New Testament History Books", 133. Cfr. SCHMIDT, Die Stellung der Evangelien, 76. 
lo cual contrasta con el anonimato de los evangelios, más cercanos a la historiografía hebrea. En segundo lugar, las biografías antiguas pretendían alabar una virtud encarnada en la vida de una persona ${ }^{89}$.

La novela ${ }^{90}$ se presenta como una narración de ficción en prosa que tiene que ver con una pareja y el Dios Eros. Su intención primordial es entretener. Tiene relación con la historiografía, de la que se distingue porque no busca la verdad $(\dot{\alpha} \lambda \hat{\eta} \theta \varepsilon\llcorner\alpha)$ de los hechos, sino tan sólo una ficción $(\pi \lambda \alpha ́ \sigma \mu \alpha)$ de cierta verosimilitud $^{91}$. Tienen continuidad con la Odisea de Homero y con Herodoto. Su cosmovisión es la del helenismo y su estilo literario es alto ${ }^{92}$. También en el mundo judío se desarrollaron novelas fueron Daniel, Susana, Judith, Esther, José y Aseneth ${ }^{93}$. Las primeras con una intención ejemplar, alentadora y confortante, mientras que ésta última tiene una función más apologética, ya que defiende el matrimonio entre dos etnias, la judía y la egipcia.

\section{REgisTROS EN MC}

Una vez presentadas las intenciones de Mc a la hora de redactar el evangelio y las de sus posibles partners, a continuación se analiza el registro del evangelio desde la perspectiva sociolingüística. Previamente se realizan algunas consideraciones sobre los registros en el griego antiguo.

El registro desde la perspectiva lingüística permite reconocer a través de unos marcadores lingüísticos el contexto en el que se desarrolla la acción

${ }^{89}$ Talbert y Dihle subrayan que las biografías antiguas tenían una función primera, al cen-

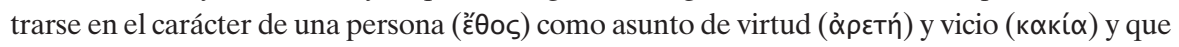
éste sería el elemento fundamental de las biografías antiguas. Estas no describen un itinerario político, social, psicológico o espiritual sino un personaje en quien se manifiestan vicios y virtudes. Así el componente moral es primero y los demás le están subordinados y su razón de ser varía según las necesidades: elogio, imitación, conversión, vida inspirada por valores superiores. Dihle, A., Studien zur griechischen Biographie, Göttingen 1956. Collins, A.Y., "Genre and the Gospels", en The Journal of Religion 75 (1995) 239-246, p. 246. AletTI, J.-N., "El Cristo narrado. Los evangelios como literatura", en Cuestiones teológicas 33:80 (2006) 207-226, p. 210.

${ }^{90}$ A diferencia de la épica está escrita en prosa. No necesita, como el drama, ni un escenario teatral ni la audiencia de una ciudad. El autor se presenta al comienzo de las mismas.

${ }^{91}$ García Gual, C., "Introducción Quéreas y Calírroe", en CARITÓn-É. JenOfonTE DE-MendozA, J. (eds.), Quéreas y Calírroe. Efesíacas. Fragmentos novelescos (=Biblioteca Gredos 134; Barcelona 2009) 9-32, p. 23.

${ }^{92}$ Bowie, E.L., "The Greek novel", en EAsterling, P.E.-KnOx, B.M.W. (eds.) The Cambridge history of classical literature. Vol. 1: Greek literature, Cambridge 1985, 683-699, p. 688.

${ }^{93}$ WILLs, L.M., The jewish novel in the ancient world, Ithaca, NY 1995. 
lingüística. El dominio social en el que se enmarca el texto de Mc es el familiar y el religioso, no el jurídico ni el institucional. El análisis del registro dará indicaciones sobre cómo las elecciones gramaticales y semánticas apuntan a una situación social recurrente.

\section{Registros en griego}

Los griegos ya habían reflexionado sobre los diferentes registros, estilos y géneros de sus obras pero sin llegar a una clara definición de los elementos que configuraban los registros ${ }^{94}$. Sin embargo, sí tenían conciencia de los rasgos preeminentes de los mismos como lo demuestran las parodias que se realizaban de algunos de ellos (Aristófanes, Luciano, Juvenal, Cátulo).

Willi señala que no se ha acometido una presentación sistemática de los registros en griego y afirma que sería una tarea hercúlea ${ }^{95}$. Estos registros son múltiples y variados en el tiempo ${ }^{96}$, siendo muchos dentro de un mismo autor e incluso dentro de una misma obra. En este sentido se pone el ejemplo de Tucídides ${ }^{97}$, donde en su misma obra tiene conciencia de los elementos de sus registros, a la vez de que está manejando una multiplicidad de registros en ella ${ }^{98}$.

No es posible en este artículo acometer un estudio de los registros en tantas obras y autores de la antigüedad ${ }^{99}$. Se ofrecen a continuación unas lí-

${ }^{94}$ Aristóteles, Retórica (ed. Q. RACIONERO) (=Biblioteca clásica Gredos 142; Madrid 1994) § 1413b,3-5 sobre la relación entre registro y género.

${ }^{95}$ WILLI, "Register Variation”, 303.

${ }^{96}$ Sobre diferentes registros en la prosa griega cfr. DovER, K.J., The evolution of Greek prose style, Oxford 1997.

${ }^{97}$ Sobre los registros de Tucídides cfr. Allan, R.J., "Sense and Sentence Complexity: Sentence Structure, Sentence Connection and Tense-Aspect as Indicators of Narrative Modes in Thucydides' Histories", en AlLAN, R.J.-BuIJs, M. (eds.), The Language of Literature: Linguistic Approaches to Classical Texts, Leiden 2007.

${ }^{98} \mathrm{Su}$ gran cantidad de sustantivos pueden reflejar su interés informativo.

${ }^{99}$ Willi ofrece un buen ejemplo. PORTER, S.E., Verbal aspect in the Greek of the New Testament: with reference to tense and mood, New York 1989, 152-153. Porter y O'Donnell identifican cuatro grandes registros: a) vulgar (papiros con asuntos personales), b) no literario (los papiros oficiales, Epicteto), c) literarios (Filón, Josefo, Polibio) y d) Aticistas (Dionisio de Halicarnaso, Plutarco). O’Donnell, M.B., "Designing and Compiling a Register Balanced Corpus of Hellenistic Greek for the Purpose of Linguistic Description and Investigation", en PORTER, S.E. (ed.), Diglossia and other topics in New Testament linguistics (=JSNTSupS 193), Sheffield 2000, 255-297, p. 277. 
neas maestras que los acotan. La primera división se establece entre registros orales y escritos. Entre los escritos se puede establecer una división fundamental entre textos literarios y documentarios ${ }^{100}$ (documentary) y otra entre la poesía y la prosa. Bentein señala cinco grandes géneros para la época postclásica: los papiros documentarios (personales y oficiales), la biografía-hagiografía, la historiografía, la novela griega y la prosa científica ${ }^{101}$. Por otro lado el dominio forense o judicial, el administrativo, el científico, el familiar, y los registros que los sustentan, han sido constatados entre los papiros descubiertos de la antigüedad ${ }^{102}$.

Los análisis de los griegos sobre sus registros eran normativos, es decir indicaban cómo se habían de construir, mientras que los actuales son descriptivos. Willi analiza varios textos comparando 23 variables ${ }^{103}$. También habría que analizar diferentes formas y recursos literarios en esas obras ${ }^{104}$. Deberían ser muchos los elementos a analizar para establecer los contornos de un registro (tiempo ${ }^{105}$, espacio ${ }^{106}$, uso de las formas retóricas, vocabulario, etc.), así que a continuación se presentan dos elementos que aparecen con regularidad en determinados registros que aparecen unidos a los géneros que podrían ser compañeros de Mc, como son la dimensión narrativa y la biográfica, las cuales aparecen en la historiografía, la novela y las biografías antiguas.

${ }^{100}$ PALME, B., "The range of documentary texys: types and categories", en BAGNALL, S. (ed.), The Oxford handbook of papyrology, Oxford 2009, 358-394.

${ }^{101}$ BENTEIN, K., Verbal periphrasis in ancient Greek: have- and be-constructions, Oxford 2016,25-27. Bentein une registro hagiográfico y biográfico e incluye al NT. Se le puede achacar su pobre reflexión sobre el problema del género. Horrocks ha propuesto una lista de marcadores del registro para tres registros: básico-no literario, oficial-científico y literario. Horrocks, G.C., Greek: a history of the language and its speakers, $\mathrm{Oxford}^{2} 2010$.

102 Renner, T., "Payrology and Ancient Literature", en BAgnAll, R.S. (ed.), The Oxford handbook of papyrology, Oxford 2009, 282-302.

${ }^{103}$ Aboga por el estudio de patrones recurrentes y no marcadores del registro. Las variables son: el número de sustantivos, de demostrativos, de pronombres, verbos en primera persona, diferentes tiempos verbales, participios, frases relativas, condicionales y longitud media de las frases, preguntas, vocativos, partículas y exclamaciones. WILLI, "Register Variation", 307.

${ }^{104}$ Para White la historiografía es discurso, y el alma del discurso son los recursos literarios (tropos). White, H., "Rhetoric and history”, en White, H. - MANuel, F.E. (eds.), Theories of History, Los Angeles 1976, 7-25, p. 7.

${ }^{105}$ De Jong, I.J.F.-NüNLIST, R., Time in ancient Greek literature, Leiden 2007.

${ }^{106}$ DE Jong, I.J.F., Space in ancient Greek literature, Leiden 2012. 


\section{a. El elemento narrativo}

El elemento narrativo es una constante en diferentes géneros como la historiografía, la biografía antigua, la novela, la épica, etc., dado que en la narrativa antigua griega el uso de elementos narrativos no estaba asociado a un género determinado ${ }^{107}$, como demuestra que los escritores de tragedia usaban elementos historiográficos, los oradores utilizan elementos trágicos, etc. Esta presencia amplia tiene que ver con cómo la narrativa es universal, porque de hecho forma parte de la mente humana ${ }^{108}$. En este sentido la historiografía actual reconoce el papel de la narrativa y la necesidad de estructurar la misma a través de una trama ${ }^{109}$ que ordene causalmente los acontecimientos. Es la diferencia con las crónicas, que carecen de ella. Actualmente ha reemplazado el estudio de las fuentes de los escritores antiguos por el estudio de cómo los diferentes autores veían el pasado $^{110}$.

Dentro del elemento narrativo existen dos elementos importantes, la trama y el tipo de narrador. Primero, la trama es el núcleo de la narración. Si la narración es la acción en sí misma, la trama es cómo el lector puede aprender de la acción ${ }^{111}$. Se pueden distinguir tramas episódicas, descripti-

${ }^{107}$ DE JONG, I.J.F., "Diachronic Narratology. The Example of Ancient Greek Narrative”, en HüHn, P. (ed.) The Living Handbook of Narratology, Hamburg 2014, 1-19, p. 1.

${ }^{108}$ Turner, M., The literary mind, Oxford 1996. Huhn habla de dos tipos de narrativa (I y II) con trama y sin ella. FuldA, D., "Historiographic Narration”, en HüHn, P. (ed.), The living handbook of narratology, Hamburg 2017, 1-14.

${ }^{109}$ KukKonen, K., "Plot”, en HüHn, P. (ed.), The living handbook of narratology, Hamburg 2017.

${ }^{110}$ Grethlein, J., "Time, Tense, and Temporality in Ancient Greek Historiography", en Oxford Handbooks Online (2014). Sobre el linguistic turn de la historiografía cfr. CLARK, E.A., History, theory, text: historians and the linguistic turn, Cambridge, MA 2004. Sobre el registro narrativo de esas obras. Grethlein, J.-RenkAKos, A.N., Narratology and interpretation: the content of narrative form in ancient literature, Berlin 2009. DE JONG, I.J.F.NÜNLIST, R.-BowIE, A.M., Narrators, narratees, and narratives in ancient Greek literature: studies in ancient Greek narrative, Leiden 2004. De Jong analiza estos elementos temporales estudiando diferentes géneros y autores de la antigüedad. DE JONG-NÜNLIST, Time in ancient Greek literature.

${ }^{111}$ En una palabra: la trama es lo que ha ocurrido efectivamente; el argumento es el modo en que el lector se ha enterado de lo sucedido. ToMACHEVSKI, B.V., "Temática”, en JAKobson, R.-Todorov, T. (eds.), Teoría de la literatura de los formalistas rusos, México, D.F. 1991, 199-232, p. 203. 
vas y tramas de revelación o de resolución ${ }^{112}$. Segundo. Sobre el tipo de narrador o cómo se presenta el autor, se ha de señalar que no se da una correlación directa entre el género y el tipo de narrador ${ }^{113}$. La historiografía, la biografía, y la lírica coral tienden a tener narradores externos (narran historias del pasado), su personalidad y opiniones son manifiestas ${ }^{114}$ (quieren enseñar una lección). La oratoria judicial y el drama tienen narradores que son internos (se ven envueltos en los eventos) y también manifiestos (quieren persuadir a sus lectores a través de sus opiniones).

\section{b. El elemento biográfico}

El elemento biográfico también aparece en varios géneros de una manera u otra. La historiografía ${ }^{115}$, la épica, la biografía, la novela, son textos narrativos que tienen como protagonistas a personajes que desarrollan diferentes acciones conectadas con una trama. Sobre el elemento biográfico Edwards ha señalado que lo biográfico es un contenido más que un género en la antigüedad ${ }^{116}$.

\section{Registro de Mc}

Una vez apuntados algunos elementos claves de los registros posibles de algunos de los géneros que serían posibles compañeros de género con Mc, se presenta a continuación un análisis del registro evangelio de Mc.

Se ha señalado que el registro de un texto permite identificar la acción que se está desarrollando, ya que éste genera restricciones a nivel lingüístico.

${ }^{112}$ La trama, como conexión causal entre acontecimientos, aparece en muchos géneros literarios. Ricoeur es el autor que ha demostrado la presencia de la misma tanto en la ficción como en la historia. Sobre la trama en los clásicos. LowE, N.J., The classical plot and the invention of western narrative, Cambridge 2000.

113 DE Jong-NünLIST-BowIE, Narrators, narratees, 545.

114 "An overt narrator seems to have a distinct personality, someone who makes his or her opinions known. An overt narrator seems to have a distinct personality, someone who makes his or her opinions known. It is a covert narrator who concentrates on showing rather than telling”. DE JoNG-NüNLIST-BowIE, Narrators, narratees, 546.

${ }^{115}$ En la antigüedad la historia se centraba en un grupo étnico.

${ }^{116}$ EdwARds, M.J., "Epilogue. Biography and the Biographic", en EdwARDS, M.J.-SwAIN, S. (eds.), Portraits: biographical representation in the Greek and Latin literature of the Roman Empire, Oxford 1997, 227-234. "First, however, it is necessary to distinguish biography from biographical interest or material. Ancient readers, like modern, found famous people fascinating”. Stadter, P., "Biography and History", en MARincola, J. (ed.), A companion to Greek and Roman historiography 2, Oxford 2007, 528-540, p. 528. 
Mc está elaborado con un registro narrativo, religioso y judío. Primero, está escrito en un registro narrativo caracterizado por la alternancia de narración y diálogos, que aparece en muchos géneros literarios de la antigüedad. Pero presenta una paradoja, se trata de un texto literario escrito en un registro no literario o científico ${ }^{117}$. Segundo, es un registro religioso dado su vocabulario y los referentes que entran en juego. Tercero se trata de un registro judeohelenístico, dado el vocabulario, los préstamos lingüísticos, el estilo literario y las referencias intertextuales que aparecen. Aun con todo esto, Mc presenta una unidad, eso sí elaborada a partir de diferentes formas literarias.

\section{a. Registro narrativo}

A la hora de analizar un registro concreto, Biber establece, dentro de la prosa, una primera distinción entre registros narrativos y argumentativos. Así mismo señala unas características del registro narrativo: verbos en pasado (aoristo, perfecto), pronombres de tercera persona ${ }^{118}$, verbos públi$\cos ^{119}$, negación sintética y oraciones con participios presentes ${ }^{120}$. Este registro narrativo presenta verbos de movimiento, diálogos y discursos, elementos contrapuestos que permiten avanzar a la narración, así como presentar los aspectos fundamentales que quiere desarrollar el autor. Esta alternancia refleja la sinergia entre acción y diálogos (showing y telling) propia de la historiografía judía. Marcos cumple con estos criterios y presenta claramente un registro narrativo. Aparecen muchos verbos de movimiento $^{121}$, alternancia de aoristos e imperfectos, uso del presente histórico para dar más viveza al relato y para señalar una transición en la narración ${ }^{122}$,

117 Joosten, J., "Varieties of Greek in the Septuagint and the New Testament.", en Paget, J.C.-Schaper, J. (eds.), The New Cambridge History of the Bible. Volume I: From the Beginnings to 600, Cambridge 2013, 22-45, p. 23.

${ }^{118}$ Con los que se refieren a los participantes en las acciones.

${ }^{119}$ Verbos como decir, declarar, contar, con los que se expresan actos comunicativos.

${ }^{120}$ Participios que se utilizan para describir y añadir imágenes a la narración.

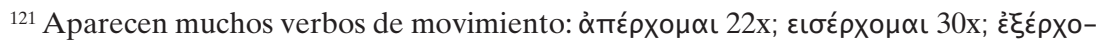

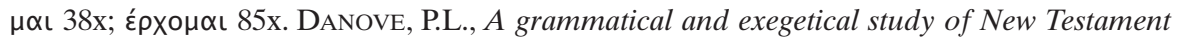
verbs of transference a case frame guide to interpretation and translation, London 2009. Sobre

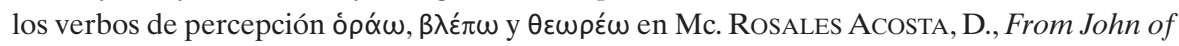
Apamea to Mark's Gospel: Two Dialogues with Thomasios: a Hermeneutical Reading of Horao, Blepo, and Theoreo, New York 2014.

122 Sobre el presente histórico OsBuRn, C.D., "The Historical Present in Mark as a TextCritical Criterion", en Biblica 64 (1983) 486-500. Sobre el tratamiento del tiempo en Mc, cfr. 
etc. Esto alternado con discursos y diálogos (aparecen múltiples verba dicendi $^{123}$ ) que hacen avanzar la trama. Este registro narrativo de Mc es innegable y aceptado en la exégesis ${ }^{124}$.

\section{b. Registro religioso}

Se ha señalado que a la hora de definir un registro existe un elemento, el campo, el topic, en el que el vocabulario es fundamental. Biber identifica el topic, como el tema del que trata como importante y cómo éste determina el vocabulario. Cada registro tiene un vocabulario específico. Si el registro era definido por la variedad lingüística utilizada en una situación social concreta, en el caso de Mc este registro tiene que ver con lo religioso ${ }^{125}$. Religioso en aquel tiempo implicaba político. Este registro religioso sería por cierto su aspecto más específico y la parte de su vocabulario más determinante. Como muestra un botón: el sustantivo que más aparece en Mc es

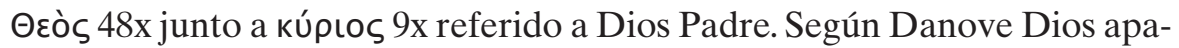
rece como agente $70 \mathrm{x}, 35 \mathrm{x}$ de ellas explícitas ${ }^{126}$. El registro religioso ${ }^{127}$ de $\mathrm{Mc}$

SChILdGen, B.D., Crisis and continuity: time in the Gospel of Mark (=JSNTSupS 159) Sheffield 1998.

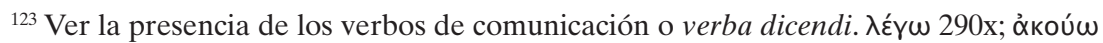

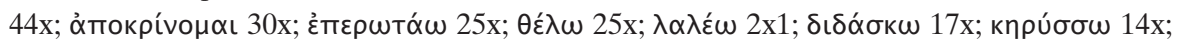

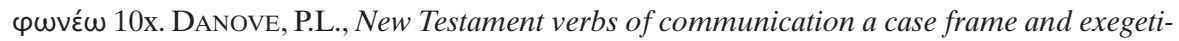
cal study, London 2015.

${ }^{124}$ RhoAds, D.M.-Dewey, J.-Michie, D., Marcos como relato: introducción a la narrativa de un evangelio, Salamanca 2002.

${ }^{125}$ Crystal y Davy analizan las peculiaridades del registro religioso, en cuanto a formalidad, sintaxis y gramática y vocabulario donde señala la presencia de palabras antiguas, el uso de términos religiosos, y el uso de palabras cuyo significado ha cambiado hasta quedar restringidas en un determinado uso al registro religioso. También analizan las características tipográficas de determinados textos religiosos. Lo cual es muy pertinente a la hora de analizar los evangelios, ya que hablan de la conciencia explícita de los copistas y de la comunidad de estar tratando con un texto singular. CRYSTAL, D.-DAVY, D., "Religious style", en Investigating English style, Harlow 1969, 147-172. Sobre la posibilidad de que Marcos fuera escrito y publicado en formato códice cfr. RoBerTs, C.H.-SKEAT, T.C., The birth of the codex, London 1983, 55 y antes en RoberTs, C.H., "The codex", en PBA (1955) 169-204.

${ }^{126}$ DANOVE, P.L., Linguistics and exegesis in the Gospel of Mark: Applications of a case frame analysis (=JSNTSupS 218), Sheffield 2001,122.

${ }^{127}$ Willi analiza el registro religioso de Aristófanes, y señala que no se puede hablar de un registro religioso en griego ático específico separado del dialecto ático, WILLI, A., "Religious Registers", en The languages of Aristophanes: aspects of linguistic variation in classical 
está determinado por su vocabulario ${ }^{128}$ y por su conexión intertextual y lingüística, gramática y semántica con los libros de la LXX, conscientes de estar refiriéndonos a una época donde política y religión caminan siempre entrelazadas. Si para algunos la sintaxis se parece al griego koiné utilizado en los textos científicos ${ }^{129}$ (Fachprosa), el topic le separa totalmente de ese registro.

\section{c. Registro judeohelenístico y vocabulario de Mc}

El registro judeohelenístico de Mc está determinado por varios factores. Mc utiliza el dialecto, el registro narrativo historiográfico, sus formas literarias, así como el mundo narrativo y la cosmovisión de la LXX. Su sintaxis y su vocabulario son los de la $\mathrm{LXX}^{130}$. El vocabulario ${ }^{131}$ de Mc per-

Attic Greek, Oxford 2003, 8-50, pero esto no se puede afirmar de la LXX. Sobre el registro religioso de la sinagoga WALSER, G., The Greek of the Ancient Synagogue: An Investigation on the Greek of the Septuagint, Pseudepigrapha and the New Testament, Lund 2001.

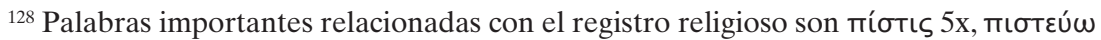

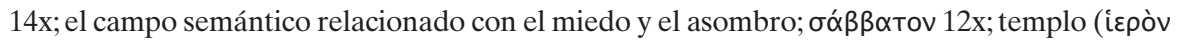

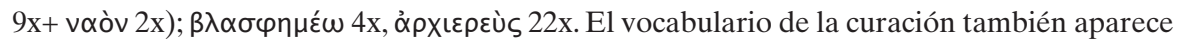

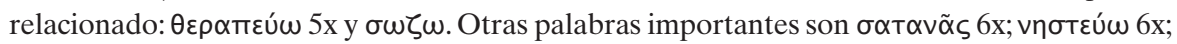

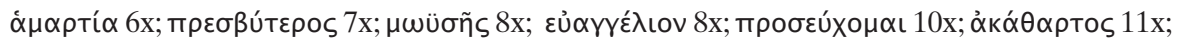

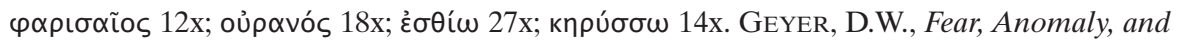
Uncertainty in the Gospel of Mark, Lanham, ML 2002. DWYER, T., The Motif of Wonder in the Gospel of Mark (=JSNTSupS 128), Sheffield 1996. Sobre el miedo y la fe en Mc, Cfr. WRIGHT, N.T., La resurrección del hijo de Dios: Los orígenes cristianos y la cuestión de Dios, Estella 2008,758 .

${ }^{129}$ La literatura científica griega es muy amplia. Está lejos de ser una clasificación neutral. Se ha estudiado desde los contenidos y no tanto desde su estilo literario. FöGEN, "Technical Literature”, 268. HofFMAnN, L.-KALVERKÄMPER, H.-WIEGAND, H.E., Fachsprachen: Ein internationales Handbuch zur Fachsprachenforschung und Terminologiewissenschaft, Berlin 1998-1999. SCHIRONI, F., “Technical Languages: Science and Medicine”, en BAKKER, E.J. (ed.), A companion to the ancient Greek language, Oxford 2010, 338-353. "Technical prose, whose authors forsook literary elaboration for maximal precision (with new "technical" vocabulary:

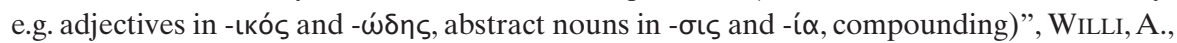
"The Language of Greek Literature", en Hose, M.-Schenker, D.J. (eds), A companion to Greek literature, Chichester, UK 2015, 443-460, p. 458.

${ }^{130}$ Hemer, C.J., "Reflections on the Nature of New Testament Greek Vocabulary", en Tyndale Bulletin 38 (1987) 65-92. SNYDER, J.A., Language and identity in ancient narratives: the relationship between speech patterns and social context in the Acts of the Apostles, Acts of John, and Acts of Philip (=WUNT 370), Tubingen 2014.

${ }^{131}$ DANOvE, Linguistics and exegesis in the Gospel of Mark. Sigue la Construction Grammar. 
tenece al griego de su tiempo como lo demostró Deissmann al constatar su aparición en papiros de la antigüedad, pero determinadas expresiones y palabras hacen referencia a conceptos que solo pueden ser entendidos dentro de este paradigma y de esta comunidad. Si se aplica el triángulo semiótico ${ }^{132}$ al griego de los papiros y al de Mc, habría que decir que coindicen los símbolos pero ni los referentes ni los contenidos mentales asociados. Es decir,

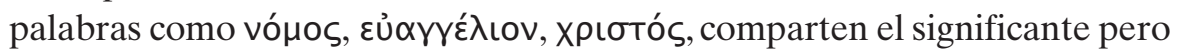
su significado y su referente serían percibidos de manera diferente por la comunidad judeohelenística y la cristiana de cómo serían percibidos por un griego de Atenas. Señala Porter acertadamente que falta un estudio del vocabulario de Mc desde los campos semánticos ${ }^{133}$. Aparecen 11099 palabras en Mc. Mateos señala que se utilizan unas 1206 palabras diferentes ${ }^{134}$. Su ratio es el mismo que el de Julio César en su guerra de las Galias ${ }^{135}$. Solo 180 palabras que no vienen en LXX, de las cuales 60 de ellas son nombres propios más 31 arameísmos y latinismos. Son pocas las palabras que no aparecen en LXX. Palabras importantes en Mc son evangelio, Cristo, hijo de Dios, enseñar y maestro, autoridad, reino de Dios, creer, seguir, el camino ${ }^{136}$. También son determinantes en este registro los lugares y protagonistas de su historia.

\section{d. Cosmovisión de $M c$}

La cosmovisión de Mc le separa de otras obras de la antigüedad. Esta cosmovisión y el mundo literario al que Marcos hace referencia (así como su estilo popular) le sitúan dentro del judaísmo, lo cual sería percibido por las élites grecorromanas como algo negativo. Por ello resulta difícil asociar la obra de Marcos con historiadores como Herodoto o Tucídides, que tienen una cosmovisión muy lejana del judaísmo. También sorprende que se pueda vincular a Mc con autores como Filostrato y Luciano, por ejemplo,

${ }^{132}$ Riemer, N., Introducing semantics, Cambridge 2010, 16.

${ }^{133}$ PORTER, “A Register Analysis of Mark 13”, p. 227 n. 24.

${ }^{134} 1330$ palabras distintas con 60 nombres propios. SWETE, H.B., The Gospel according to St. Mark: the Greek text with introduction, notes and indices, London 1898, xliv.

${ }^{135}$ Dice Edwards, Mark, que usa el mismo ratio de vocabulario que César en las Galias. EDWARDS, J.R., The Gospel according to Mark, Grand Rapids, MI 2002,10-11.

${ }^{136}$ La palabra vópos significa en griego costumbre y en el NT y en la LXX hace refe-

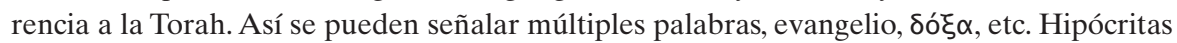
sería un nuevo uso religioso. CAmery-HogGatt, J., Irony in Mark's Gospel: text and subtext, Cambridge 1992, 148. 
que despreciaban al cristianismo y alababan prácticas como la pederastia. Las comunidades discursivas a las que se dirigen esos distintos textos son radicalmente distintas. Mc asume y continúa el mundo narrativo de los LXX. Otros elementos a tener en cuenta son los personajes que aparecen como continuación de las obras de LXX, el protagonismo de Dios, el anonimato de la obra, las normas literarias, los lugares, etc.

\section{e. Excursus. Registro en Mc según SFL}

Dada la importancia de una teoría lingüística como es la lingüística funcional (SFL) y dada su relación genética con la sociolingüística, se analiza a continuación el registro de Mc desde esta perspectiva.

Stanley Porter ha estudiado el registro del evangelio de $\operatorname{Marcos}^{137}$ utilizando las herramientas de la SFL y ha aplicado su estudio a Mc 13 y Mc $16,1-8^{138}$. Porter critica la visión de que Marcos es un texto sencillo y analiza su registro, utilizando las categorías de modo, tenor y campo de Halliday. El modo de Marcos es el de una narración escrita seguramente pensada para ser leída en alto y señala que el estilo paratáctico, lejos de ser una imposición de la influencia semítica, podría venir impuesto por el objetivo de señalar los acontecimientos como siguiendo una sucesión necesaria, además de señalar que partículas como عủӨús aportan cohesión al relato, el cual sigue una estructura cronológica y temática. Su estudio analiza la cohesión del texto, por el uso del vocabulario, el uso del adverbio عủӨús y de las estructuras paratácticas y el uso de la tercera persona. El tenor del texto de Mc es monolingüe, donde el narrador presenta a todos los protagonistas. Analiza el uso de las personas y señala que se utiliza poco la tercera persona para referirse a Jesús. Estudia la modalidad de los verbos y señala que predomina la aserción. Así mismo estudia las relaciones entre

${ }^{137}$ Porter, S.E., "Register in the Greek of the New Testament: Application with Reference to Mark's Gospel”, en CARROLL R., M.D. (ed.), Rethinking contexts, rereading texts: contributions from the social sciences to biblical interpretation (=JSOTSupS 299), Sheffield 2000, 209-229. Cfr. su presentación de la SFL en PorTer, S.E., "Systemic Functional Linguistics and the Greek Language: The Need for Further Modeling”, en PorTER, S.E.-FEWSTER, G.P.-LAND, C.D. (eds.), Modeling Biblical Language: selected papers from the McMaster Divinity College Linguistics Circle, Leiden 2016, 9-47.

${ }^{138}$ Porter, "A Register Analysis of Mark 13", Porter, S.E., "Verbal aspect and Discourse Function in Mark 16:1-8: Three Significant instances", en CORLEY, J.-SKEMP, V.T.M. (eds.), Studies in the Greek Bible: essays in honor of Francis T. Gignac, S.J., Washington, DC 2008, 123-137. 
Jesús y sus discípulos y oponentes. El campo apunta a la intención del escrito. Dos aspectos son importantes: la preponderancia del campo semántico referido a la comunicación y el de los verbos de movimiento. Jesús es importante y presentado por lo que dice y por su continuo movimiento hacia Jerusalén.

Una vez analizado el registro de Mc, Porter aporta tres conclusiones y ofrece una alternativa a los estudios sobre el género. Primera, Porter pone de manifiesto que es central el término evangelio y el verbo predicar, no tanto por sus recurrencias sino por la significatividad de sus apariciones. Segunda, Mc está dirigido a una comunidad que ya está convencida de quién es Jesús ${ }^{139}$. Tercera, seguramente Mc fue escrito antes de un conflicto entre la comunidad y el mundo romano. El estudio desde la perspectiva de la SFL de Marcos, refuerza las conclusiones tradicionales del estudio con el método histórico-crítico.

\section{GÉNERO Y REGISTRO DE MC EN CONEXIÓN SINÉRGICA}

Una vez presentadas en detalle las intenciones de Mc como claves para entender su género y las de sus posibles compañeros de género, y después de haber analizado el registro de Mc es el momento de ponerles en relación. Si el género permite acercarse a la intención del relato y el registro permite analizar cómo se desarrolla éste a nivel gramatical y lingüístico se puede afirmar en el caso de Marcos lo siguiente.

Primero, su género y su registro están en relación sinérgica dado que las intenciones comunicativa e histórica de Marcos son desarrolladas por su registro narrativo (verbos en pasado, verbos de movimiento y verbos comunicativos, uso de la tercera persona, adverbios temporales, etc.). La trama de Marcos pone de manifiesto el elemento narrativo, mientras que el anonimato del autor, así como las escasas manifestaciones del narrador en la obra (Mc 13,14) alejan a Mc de los géneros más helenísticos.

Segundo, esta relación sinérgica entre su género y su registro refuerza la vinculación de Mc con la LXX, como lo prueba que son los únicos libros citados en él y como corrobora su prólogo que opta por vincularse con la historiografía judía. Su género literario encuentra analogías claras entre los libros de la LXX. De ésta toma su variante dialectal (sintaxis) y registro.

${ }^{139}$ PORTER, "Register in the Greek of the New Testament", 228. 
Esto se ve confirmado por el registro que utiliza Mc, especialmente en su vocabulario cercano al de LXX y al utilizar un registro narrativo y religioso, cercano al de los libros históricos y proféticos del AT. El dominio social que se transparenta es el de la comunidad cristiana, o el de la sinagoga, en todo caso, un dominio familiar y religioso, alejado de las élites.

Tercero. Los posibles partners de Mc, como son la historiografía helenística, las biografías antiguas y la novela optan por un registro más helenístico (no bárbaro, étnicamente centrado en Grecia y sus colonias), como lo demuestran su vocabulario y estilo. Su cosmovisión y mundo narrativo conectan con la épica griega clásica, así como su estilo que es cercano a la variedad alta del griego de su época. Marcos comparte con la historiografía helenística el deseo de interpretar determinados sucesos reales y con las biografías la centralidad de un personaje. Con la novela solo el registro narrativo, porque su estilo e intención son antagónicas con Mc.

Se puede presentar una tabla que permita ver la relación entre estos elementos.

\begin{tabular}{|c|c|c|c|c|c|}
\hline Obras & Género & Registro & Estilo & Cosmovisión & Autor \\
\hline Mc & $\begin{array}{l}\text { Presentar a Jesús como Hijo } \\
\text { de Dios } \\
\text { Interpretativa } \\
\text { Hermenéutica } \\
\text { Cohesiona su comunidad }\end{array}$ & $\begin{array}{l}\text { Narrativo } \\
\text { Religioso } \\
\text { Judío } \\
\text { Biográfico }\end{array}$ & Bajo & Judeohelenística & Anónimo \\
\hline Historiografía & $\begin{array}{l}\text { Narrar sucesos recientes } \\
\text { Intención política } \\
\text { Fama autor }\end{array}$ & $\begin{array}{l}\text { Narrativo } \\
\text { Político }\end{array}$ & Alto & Helenística & $\begin{array}{l}\text { Conocido } \\
\text { Manifiesto }\end{array}$ \\
\hline $\begin{array}{l}\text { Historiografía } \\
\text { judía }\end{array}$ & $\begin{array}{l}\text { Narrar sucesos pueblo judío } \\
\text { Interpretación teológica de la } \\
\text { realidad }\end{array}$ & $\begin{array}{l}\text { Narrativo } \\
\text { Religioso } \\
\text { Político } \\
\text { Judío }\end{array}$ & Medio & Judía & Anónimo \\
\hline Biografía & $\begin{array}{l}\text { Fama autor } \\
\text { Reforzar virtud } \\
\text { Narrar sucesos reales }\end{array}$ & $\begin{array}{l}\text { Narrativo } \\
\text { Biográfico }\end{array}$ & Alto & Helenística & $\begin{array}{l}\text { Conocido } \\
\text { Manifiesto }\end{array}$ \\
\hline Novela & $\begin{array}{l}\text { Entretener } \\
\text { Narrar sucesos ficticios }\end{array}$ & $\begin{array}{l}\text { Narrativo } \\
\text { Erótico }\end{array}$ & Alto & Helenística & $\begin{array}{l}\text { Conocido } \\
\text { Manifiesto }\end{array}$ \\
\hline $\begin{array}{l}\text { Novela } \\
\text { judía }\end{array}$ & $\begin{array}{l}\text { Exhortar } \\
\text { Entretener } \\
\text { Narrar sucesos ficticios }\end{array}$ & $\begin{array}{l}\text { Narrativo } \\
\text { Religioso } \\
\text { Judío }\end{array}$ & Medio & Judeohelenística & Anónimo \\
\hline
\end{tabular}


La interrelación entre género y registro en cada una de estas obras pone de manifiesto la necesidad de una mirada más amplia al problema del género para ser abordado en relación con otros elementos que ayuden a comprender su relato.

\section{CONCLUSIón}

Se ha analizado el género literario de Mc desde las diferentes intenciones subyacentes en él y posteriormente se han definido algunos rasgos del registro de Mc. Son dos elementos importantes, pero no suficientes para poder comprender una obra tan compleja como es Mc.

Marcos es un texto literario, escrito en un género próximo a la historiografía helenística y judía, a las biografías de la antigüedad, y de la misma manera resulta exponente de un género nuevo, como demuestran sus seguidores Mt y Lc. Estaría en la zona de intersección de esos géneros, que tienen como centro los prototipos característicos de cada uno de ellos. Especialmente significativa es la relación con la historiografía judía, más concretamente con los relatos protagonizados por los profetas, la saga de David y los ciclos de Elías y Eliseo. Con la historiografía judía comparte mundo literario, cosmovisión, dialecto y protagonistas, así como anonimato y referencias intertextuales. Su cuidada estructura literaria y narrativa, recientemente descubierta, contrastan con su estilo bajo. Este estilo popular (elaborado con frases cortas, el uso de la parataxis, sus construcciones gramaticales cercanas al griego de traducción de la LXX y su uso de extranjerismos latinos y arameos), así como su anonimato y la ausencia de presentación de sus fuentes, provocaron que fuera identificado como un texto no literario, dando lugar a una interpretación errónea.

El estudio del registro de Mc parece que confirma esta centralidad narrativa. Su registro presenta claramente elementos narrativos y religiosos y le sitúa cercano al registro judeohelenístico, especialmente por su vocabulario y por sus construcciones sintácticas y gramaticales, que siendo plenamente pertenecientes al griego koiné, le colocan en el ámbito de una comunidad discursiva que siendo cristiana conoce y valora las tradiciones de la LXX, aceptándolas como revelación de Dios, lo cual junto con su estilo bajo, le separa de las obras provenientes de la literatura clásica griega que manejan un estilo y una cosmovisión muy diferente. Su domino sociolingüístico es el familiar y el religioso. 
Marcos podía haber elegido otro género para comunicar su mensaje. Podría, como Pablo, haber escrito cartas o utilizar otros géneros como los diálogos de Platón. Podría haber utilizado un estilo más alto (como 1Ped), y otro registro, por ejemplo más helenístico como el que aparece en el prólogo de Lucas. Sin embargo, eligió la narración, centrada en un personaje y en su relación con unos discípulos en el marco de un conflicto que desemboca en la muerte pero que se ve superado por la resurrección de su protagonista.

Si el registro muestra qué estás haciendo y con quiénes, entonces Marcos está narrando una historia ocurrida en Galilea y Jerusalén, la historia de Jesús y sus discípulos y se está dirigiendo a una comunidad cristiana simpatizante con el judaísmo en un dominio familiar y religioso. Si el género apunta a la estrategia social para cumplir con una tarea, Marcos está utilizando un género cercano al de la historiografía judía (seguramente unido a otros) para que su relato quede enmarcado en la historia de Israel, tal y como se encuentra en los libros de la LXX. En este sentido parece que su registro le aleja de la historiografía helenística y de las biografías y la novela.

Este artículo ha querido aplicar las herramientas de la sociolingüística a Mc para situarlo en su contexto grecorromano, judeohelenístico y cristiano para salir del círculo cerrado en el que se encuentran los estudios sobre el género literario e introducir nuevas variables en la ecuación que permitan poner más luz al problema del género. En este sentido, el análisis del registro de Mc, así como la comparación de Mc con otros posibles géneros se habrá de establecer no sólo sobre la comparación de determinadas características formales sino desde la interrelación género-registro de esas posibles obras que podrían ser modelo para Mc. 